\title{
The Psychologist:
}

Practice \& Research Journal

\section{The relationship between self-compassion and chronic depression: a cross-sectional clinical study}

\author{
José Eduardo da Silva ${ }^{1}$, Sónia Catarina Simões ${ }^{2}$ \\ ${ }^{1}$ Villa Ramadas International Treatment Centre, Portugal \\ ${ }^{2}$ Instituto Superior Miguel Torga, Portugal
}

Corresponding author: José Eduardo da Silva I jeduardo@villaramadas.com
Received:

27 October 2017

Accepted:

16 September 2018

\begin{abstract}
Background: At present, depression is the world's most common psychopathology. Self-compassion is a psychological concept that has shown promise regarding its impact on psychopathology. Despite a vast literature studying the relationship between depression and self-compassion, few studies about this association were done in clinical samples.

Goals: This study sought to analyze the associations between self-compassion, its dimensions and symptomatology of depression, during and after a therapeutic intervention.

Methods: A non-probabilistic sampling method was used. All participants had been diagnosed with persistent depression disorder (dysthymia) and were treated in a residential therapeutic community for a period of six to eight months. The original sample was divided into two groups: during (In-Treatment) and after treatment (one-year Post-Treatment). The assessment protocol was composed of Beck Depression Inventory (BDI II), Self-Compassion Scale (SELFCS) and sociodemographic characterization.

Results: The sample was composed of 63 participants, 28 females and 35 males (age: $M=32.84, S D=10.24$ ). Women presented lower levels of self-kindness and self-compassion (total score), and higher levels of all the negative dimensions of SELFCS. Patients with moderate or severe symptoms of depression indicated a lower total score of self-compassion as well as higher scores in all the negative dimensions; patients having undergone previous treatments showed higher levels of symptomatology of depression. The group assessed after the intervention presented higher levels of self-compassion and lower levels of over-identification, when compared to the group that was assessed still undergoing treatment. Finally, the self-judgment dimension of the SELFCS stands out as a predictor of depression for the total sample and the SELFCS's isolation dimension is a predictor of BDI's scores for the group undergoing treatment.

Discussion: Although most of the results are in line with similar findings of the existing literature about the relationship between the studied variables, some were unexpected, and may guide the direction of future studies and the application of these concepts within the clinical context.
\end{abstract}

Keywords: Chronic Depression, Dysthymic disorder, Self-Compassion, Self-Judgment.

\section{Introduction}

Depression is not only one of the most common psychiatric disorders that human beings face today (Kessler et al., 2005), but also one of the most common and serious affective disorders in Western society. According to the World Health Organization (WHO, 2017), around 4,4\% of the world's population suffers from depression, which ranks depression as a distinct contributor to global disability.

Mood disorders contribute on a large scale to suicide deaths, which represent $1.5 \%$ of all deaths around the world (WHO, 2017). For instance, around 1 in 10 men and 1 in 4 women present clinical depression in the 
United Kingdom (Horn, 2012) and, according to the Diagnostic and Statistical Manual of Mental Disorders (DSM-5; American Psychiatry Association [APA], 2013), the prevalence at 12 months in the United States is about $0.5 \%$ for Persistent Depressive Disorder (previously reported as dysthymia) and $1.5 \%$ for Chronic Major Depressive Disorder.

The clinical presentation of chronic depression accounts for close to one third of all the cases of depression and presents a high level of comorbidity. Chronic depression is diagnosed in 3\% of the United States population. Despite its high prevalence, according to Michalak and Lam (2002), it is frequently misdiagnosed and inadequately treated.

In Portugal, there are no population-based data to reliably establish the prevalence of the various types of mood disorders (Gusmão, Xavier, Heitor, Bento, \& Almeida, 2005), but the World Mental Health Survey Initiative (Xavier, Baptista, Mendes, Magalhães, \& Caldas-de-Almeida, 2013) gave us specific data regarding the annual prevalence in Portugal of mood disorders in general, revealing a percentage of $7.9 \%$, amongst the highest in Western society.

Regarding the prevalence of depression according to gender, Piccinelli and Wilkinson (2000) found that, with few exceptions, the prevalence of depressive disorders is higher in females than in males, beginning at mid-puberty and remaining through adult life. Various possible factors have been considered, including adverse experiences in childhood (Rodgers, 1994; Veijola et al., 1998), prior mood and anxiety disorders (Bifulco, Brown, Moran, \& Ball, 1998; Parker, Wilhelm, \& Asghari, 1997), social roles, cultural norms (Bebbington, 1996, 1998) and, more recently, the vulnerability expressed by personality characteristics and coping style (Kelly, Tyrka, Price, \& Carpenter, 2008).

Depression has been characterized as a pathological state, in which there is (not necessarily in a cumulative way): loss of interest and pleasure, disturbance of sleep and appetite, motor slowing, feelings of uselessness and guilt, cognitive disorders, lack of energy and fatigue, thoughts of death or suicide (Kaplan \& Sadock,
1997). All these possible symptoms of depression significantly impact quality of life (Coutinho, Gontiès, Araújo, \& Sá, 2003).

According to the DSM-5 (APA, 2013), when the symptomatology of depression continues for a minimum period of 2 years, it is called Persistent Depressive Disorder (also known as dysthymia), a clinical representation that equates to chronic depression. If during this period of depression symptomatology there is an occurrence of a major depressive episode, the diagnosis is both Major Depressive Disorder and Persistent Depressive Disorder (dysthymia).

\section{The Emergence of Self-Compassion in Psychology}

More than the traditional approach of pursuing the elimination of psychopathology as the goal of treatment, there is a growing interest in redefining mental health as the presence of optimal well-being and not only the absence of psychopathology (Keyes, 2005).

There is supporting evidence that positive mental health and psychopathology function along different continua, and are only moderately interrelated (Keyes, 2005; Lamers, Westerhof, Bohlmeijer, ten Klooster, \& Keyes, 2011; Weich et al., 2011). Positive mental health and psychopathology are not exact opposites and must be considered as different indicators of mental health. This, as indicated by Trompetter, Kleine and Bohlmeijer (2016), makes positive mental health in itself an important end-point of both scientific study and intervention. However, in order to advance knowledge and to adapt clinical interventions aimed to develop positive mental health, we need to better understand the action mechanisms by which clinical interventions have their positive effects (Trompetter et al., 2016).

A relatively new concept in Western psychology, that also seems to be a resilience mechanism in the relationship between psychopathology and positive mental health, is self-compassion (Trompetter et al., 2016). The related concept of compassion (Neff, 2003a) involves the experience of being touched by the suffering of others and the emergence of feelings 
of kindness and the desire to alleviate their suffering (Wispe, 1991). It involves the adoption of a nonjudgmental understanding attitude towards those who do wrong or fail, seeing their actions in the context of shared human fallibility (Neff, 2003a).

Self-compassion is compassion turned inward (Neff, 2012), and entails the adoption of an accepting posture towards less positive aspects of life and of ourselves, even and particularly in moments of suffering. According to Neff (2003a), self-compassion involves three basic components: (a) self-kindness (kindness and understanding towards oneself rather than judgment and self-criticism); (b) common humanity (conception of one's experience as being a part of the larger human experience and not as separating and isolating); and (c) mindfulness (being aware of one's painful thoughts and emotions rather than overidentifying with them).

Regarding differences in self-compassion according to gender, past research findings have been inconsistent. Several studies have found lower levels of self-compassion in females than in males (Neff, 2003a; Neff, Hseih \& Dejitthirat, 2005; Neff \& McGehee, 2010; Raes, 2010; Yarnell \& Neff, 2013), while others have not found these differences to be significant (Iskender, 2009; Neff, Pisitsungkagarn, \& Hseih, 2008; Neff, Kirkpatrick, \& Rude, 2007; Neff \& Pommier, 2013; Raque-Bogdan, Ericson, Jackson, Martin, \& Bryan, 2011). A relatively recent meta-analysis conducted by Yarnell and colleagues (2015), revealed that males had slightly higher levels of self-compassion when compared with females, and that this difference was larger when samples included a higher percentage of individuals from ethnic backgrounds.

Various studies have shown that self-compassion is indeed a strong predictor of well-being and mental health (Neff, 2003a, 2003b; Neff, Rude, \& Kirkpatrick, 2007). Self-compassion also appears positively associated with life satisfaction, happiness, social connectivity, optimism, curiosity and exploration, and positive affectivity in general (Neff et al., 2007). It has been found that feelings of self-compassion correlate with higher cerebral activity in the pre-frontal cortex, an area associated with contentment and optimism
(Lutz, Greischar, Rawlings, Ricard, \& Davidson, 2004). The body of research that suggests the importance of studying self-compassion and its cultivation both in clinical and non-clinical samples is growing (see Barnard \& Curry, 2011; Galante, Galante, Bekker, \& Gallacher, 2014; Gilbert \& Procter, 2006; Hofmann, Grossman \& Hinton, 2011; Neff, 2015).

Many studies have already explored the relationship between self-compassion and depression. Neff, Rude and Kirkpatrick (2007) revealed a negative association between self-compassion and self-judgment, depression, anxiety, rumination, thought suppression, and negative affectivity in general. A meta-analysis by MacBeth and Gumley (2012), including about 4000 subjects, has shown a mean effect size of $r=-.54$ between symptoms of depression and self-compassion. Krieger, Altenstein, Baettig, Doerig and Holtforth (2013) indicated that participants going through a major depression episode showed significantly lower levels of self-compassion than people who had never been depressed. One of the few longitudinal studies looking at this relationship, by Raes (2011), indicated that levels of self-compassion at baseline measurements (first of two assessments separated by a 5month period) were significantly negatively associated with symptomatology of depression. More recently, Krieger, Berger and Holtforth (2016), studied the reciprocal effects between symptoms of depression and self-compassion, and found that lack of selfcompassion significantly predicted subsequent symptoms of depression, whereas symptoms of depression did not predict levels of self-compassion. The same was found for the relationship between the presence of a major depression episode and self-compassion.

There are few studies (e.g., Van Dam, Sheppard, Forsyth, \& Earleywine, 2011; Krieger et al., 2013) that have assessed self-compassion in clinically depressed patients. This information is important to better understand the relationship between the different dimensions of self-compassion and depression, and also when considering the integration of self-compassion in interventions for different types of clinical depression (Krieger et al., 2013). Lastly, a systematic review by Leaviss and Uttley (2014), including fourteen studies about compassion-focused therapy (CFT), 
indicated favorable results to CFT as an intervention for mood disorders, particularly when high levels of self-criticism are present.

The primary objective of the study here presented was to characterize the relationship between symptoms of depression and the different dimensions of self-compassion in clinically depressed patients according to their moment of treatment (currently in treatment or after treatment). Secondly, we sought to explore the association between these variables in clinically depressed patients, according to some variables, some of them understudied: gender, severity level of depression, and the existence of previous treatments.

\section{Methods}

This is an observational non-randomized clinical study, carried out with patients diagnosed with persistent depressive disorder, also known as dysthymia. The sample was composed of two different groups according to moment of psychotherapeutic treatment (during and after therapeutic intervention).

The psychotherapeutic treatment was conducted in a residential treatment centre (VillaRamadas) with a duration of approximately 180 days. The model of intervention was the Change \& Grow model, which organizes the treatment into five principles: truth, acceptance, gratitude, love and responsibility. This model integrates cognitive and behavioral therapy, third generation therapies and positive psychology into both individual and group sessions. On week days, each patient had 1 individual therapy session and 5 group sessions (e.g. psychoeducation, mindfulness).

\section{Participants}

The sample of the study was recruited according to a non-probabilistic sampling, and was composed of Portuguese patients diagnosed with Persistent Depressive Disorder, treated in VillaRamadas. The initial sample was divided into two different groups, according to the stage of treatment: one group composed of patients that were still in the treatment program (In-treatment) at the moment of data collection, and another group composed of patients that had completed the treatment program at least 1 year before (Post-Treatment).

The inclusion criteria were defined as: both genders; suffering from a Persistent Depressive Disorder, as diagnosed at the time of admission into the in-patient care program at the residential treatment centre (VillaRamadas). This diagnosis was confirmed by the centre's psychiatrist, in accordance with DSM-V (APA, 2013), during the first week of residence. Included patients had also to be fluent of Portuguese language, willing to participate in the study and to give informed consent.

The exclusion criteria were, for the In-Treatment group, not having been in treatment for at least two weeks (i.e., having interrupted the treatment), and for the Post-Treatment group, not having finished treatment (either voluntary or disciplinary discharge).

\section{Measurements \\ Beck depression inventory - II (BDI-II)}

Symptomatology of depression was measured with the Beck Depression Inventory II (BDI-II) developed by Beck, Steer and Brown (1996), one of the most commonly used instruments both in research and practice to assess the presence and severity of depression. In the present study, the Portuguese version, by Ponciano, Cardoso and Pereira (2004), was applied. The inventory is composed of 21 sets of statements, representing items that assess symptoms corresponding to DSM-IV mood disorders diagnosis criteria (APA, 1994). The options of answer include four levels of severity, with scores ranging from zero to three (for each item). The total score is the sum of all responses and can vary from zero to 63 (the higher the value, the higher the level of depression).

The severity of symptomatology of depression was measured using an adaptation of the BDI-II cut-off points. The BDI-II provides the following cut-off points: without depression (0-4); mild depression (5-7); moderate depression (8-15); severe depression 
(more than 16; Beck et al., 1961). In the present study, we considered the participants as divided into two groups: without/mild depression (0-7) and moderate/severe depression (>7).

With regard to the inventory's psychometric properties, Ponciano and colleagues (2004) obtained a Cronbach's alpha of .93, which reveals very good internal consistency. In the present study, Cronbach's alpha was of .80 , still considered a good value (Pestana \& Gageiro, 2008).

\section{Self-compassion scale (SCS)}

Self-compassion was assessed with the Self-Compassion Scale (SCS; Neff, 2003b, 2015). This is a self-report inventory composed of 26 items, that can be grouped into six subscales: three positive dimensions (selfkindness, common humanity and mindfulness) and three negative dimensions (self-judgment, isolation and over-identification). Each item was rated on a 5point Likert scale ( 1 = strongly disagree to $5=$ strongly agree). In the current study, we used the Portuguese version of the SCS, validated by Castilho and Gouveia (2011). The reliability values were very good for both the original study ( $\alpha=.92$; Neff, 2003a) and the Portuguese version ( $\alpha=.94$; Castilho \& Gouveia, 2011). In the present study, the Cronbach's alpha for each of the dimensions were: self-kindness .84 , common humanity .84, mindfulness .70, self-judgment .79, isolation .74, and over-identification .83. The reliability value for the global scale $(\alpha=.94)$ was very good (Pestana \& Gageiro, 2008).

\section{Procedures}

The research protocol was applied in the VillaRamadas treatment centre by the clinical psychologists who integrates the therapeutic staff. The data were collected from December of 2014 until February of 2015.

For the In-Treatment group, every patient who met the inclusion criteria was approached by their own individual therapist about the possibility of participating in the study. If they agreed, the research protocol was administrated by the psychologist in the centre, during the period reserved for the daily individual session (so as to not affecting the therapeutic routine of the other patients).
For the Post-treatment group, the patients who had successfully completed treatment at least 1 year before were approached during the monthly after-care session at the centre (conducted by the psychologists of the therapeutic staff). The study was explained in person and, if they agreed to participate, administered also in person.

\section{Data analysis}

The statistical analysis of the data was conducted using the Statistical Package for Social Sciences 21 (SPSS 21).

Preliminary analyses were made to confirm the assumption of normality for every variable. For this purpose, skewness and kurtosis values were taken into consideration (Kline, 2005). For the present sample, every variable revealed skewness values between 1.32 and -0.58 , and kurtosis values between 1.79 and -0.48. Therefore, it was considered that data followed the assumptions of normality, indicating its suitability for parametric tests.

Product-moment Pearson analyses were performed to explore the relationship between main variables, namely BDI II scores and self-compassion (SELFCS) scores, for the total sample and for each of the groups under study.

Student's t-tests were used to explore the differences of BDI-II scores and SELFCS scores according to gender, the existence of previous treatments, moment of treatment (In-treatment and Post-treatment). T-test was also used to compare mean values of SELFCS between the two considered levels of depression (on basis of BDI-II scores).

Stepwise regression analysis was used to explore the different dimensions of self-compassion as predictors for depression (BDI-II).

\section{Ethical issues}

The authors of both psychological instruments were contacted with the intent of asking permission to use these measurement tools. A research assistant presented all participants with an overview of the study, 
explained a detailed data privacy statement, and informed the participants about the anonymization of their personal data. Subsequently, verbal informed consent was obtained.

\section{Results}

\section{Sample characterization}

The complete sociodemographic characterization of the sample can be seen in Table 1.

Overall, $55.6 \%$ of the sample were male and $44.4 \%$ female, with ages from 15 to 57 years old $(M=32.84$; $S D=10.24)$.
The In-treatment group was composed of 32 patients, with a distribution of $59.4 \%$ male and $40.6 \%$ female, between 15 and 50 years of age $(M=30.78 ; S D=9.54)$. The Post-treatment group was composed of 31 patients, $51.6 \%$ men and $48.4 \%$ women, between 16 and 57 years of age $(M=34.97 ; S D=10.65)$.

\section{Differences between In- and Post-treatment groups} Significant differences were found regarding self-compassion between the In-treatment and Posttreatment groups (Table 2). The Post-treatment group presented higher scores of common humanity $\left(t_{(60)}=\right.$ 2.05, $p=.045)$, mindfulness $\left(t_{(60)}=2.18\right.$, $p=.033)$, a higher global score of self-compassion $\left(t_{(54)}\right.$ $=2.21, p=.031)$, and a significantly lower score of over-identification $\left(t_{(59)}=-2.28, p=.026\right)$.

Table 1. Sociodemographic characterization of the sample

\begin{tabular}{|c|c|c|c|c|c|c|}
\hline & \multicolumn{2}{|c|}{$\begin{array}{l}\text { Total sample } \\
(\mathrm{N}=63)\end{array}$} & \multicolumn{2}{|c|}{$\begin{array}{l}\text { In-treatment group } \\
(\mathrm{n}=32)\end{array}$} & \multicolumn{2}{|c|}{$\begin{array}{l}\text { Post-treatment group } \\
\qquad(\mathrm{n}=31)\end{array}$} \\
\hline & $n$ & $\%$ & $n$ & $\%$ & $n$ & $\%$ \\
\hline \multicolumn{7}{|l|}{ Gender } \\
\hline Male & 35 & 55.6 & 19 & 59.4 & 16 & 51.6 \\
\hline Female & 28 & 44.4 & 13 & 40.6 & 15 & 48.4 \\
\hline \multicolumn{7}{|l|}{ Marital status ${ }^{*}$} \\
\hline Single & 42 & 67.7 & 22 & 70.9 & 20 & 64.5 \\
\hline Married & 9 & 14.5 & 3 & 9.7 & 6 & 19.4 \\
\hline Divorced & 5 & 8.0 & 3 & 9.7 & 2 & 6.5 \\
\hline Cohabitation & 6 & 9.8 & 3 & 9.7 & 3 & 9.6 \\
\hline \multicolumn{7}{|l|}{ Education } \\
\hline Elementary School & 1 & 1.6 & 0 & 0 & 1 & 3.2 \\
\hline Middle School & 14 & 22.2 & 4 & 12.5 & 10 & 32.3 \\
\hline High School & 30 & 47.6 & 18 & 56.3 & 12 & 38.7 \\
\hline University & 18 & 28.6 & 10 & 31.2 & 8 & 25.8 \\
\hline \multicolumn{7}{|l|}{ Professional situation } \\
\hline Employed & 21 & 33.3 & 6 & 18.8 & 15 & 48.4 \\
\hline Unemployed & 25 & 39.7 & 13 & 40.6 & 10 & 32.2 \\
\hline Retired & 1 & 1.6 & 0 & 0 & 1 & 3.2 \\
\hline Student & 16 & 25.4 & 13 & 40.6 & 5 & 16.2 \\
\hline
\end{tabular}

Although the Post-treatment group presented a lower BDI-II mean score than the In-treatment group, the difference was not significant.

\section{Differences in SELFCS according to gender, previous treatment and BDI-II severity level}

Significant differences were found between genders regarding the global score of self-compassion $\left(t_{(51)}=-2,67, p=.010\right)$, as well as for the following dimensions: self-kindness $\left(t_{(60)}=-2.05, p=.045\right)$, selfjudgment $\left(t_{(61)}=2.06, p=.044\right)$, isolation $\left(t_{(59)}=3.36\right.$, $p=.001)$ and over-identification $\left(t_{(59)}=2.94, p=.005\right)$. Men presented higher mean scores of self-kindness as well as a higher total score of self-compassion, and lower levels in all negative dimensions (Table 3). 
Table 2. BDI-II and SEFCLS scores for in-treatment and post-treatment samples

\begin{tabular}{|c|c|c|c|c|c|c|c|c|c|c|c|}
\hline & \multicolumn{3}{|c|}{ Total sample } & \multicolumn{3}{|c|}{ In-Treatment } & \multicolumn{3}{|c|}{ Post-Treatment } & \multirow[b]{2}{*}{$t$} & \multirow[b]{2}{*}{$p$} \\
\hline & $n$ & $M$ & $S D$ & $n$ & $M$ & $S D$ & $n$ & $M$ & $S D$ & & \\
\hline BDI-II total score & 53 & 7.87 & 6.19 & 27 & 8.70 & 6.39 & 26 & 7.00 & 5.97 & -1.00 & .321 \\
\hline \multicolumn{12}{|l|}{ SELFCS } \\
\hline Self-kindness & 62 & 13.53 & 3.90 & 31 & 12.71 & 3.45 & 31 & 14.35 & 4.20 & 1.69 & .097 \\
\hline Common humanity & 62 & 12.94 & 3.44 & 31 & 12.06 & 3.78 & 31 & 13.81 & 2.87 & 2.05 & $.045 *$ \\
\hline Mindfulness & 62 & 11.77 & 2.86 & 32 & 11.03 & 2.88 & 30 & 12.57 & 2.66 & 2.18 & $.033^{*}$ \\
\hline Self-judgment & 63 & 15.60 & 4.05 & 32 & 16.38 & 4.26 & 31 & 14.81 & 3.73 & -1.55 & .126 \\
\hline Isolation & 61 & 12.03 & 3.33 & 31 & 12.48 & 3.27 & 30 & 11.57 & 3.38 & -1.08 & .286 \\
\hline Over-identification & 61 & 12.38 & 3.52 & 31 & 13.35 & 3.38 & 30 & 11.37 & 3.42 & -2.28 & $.026 *$ \\
\hline Total & 56 & 75.79 & 17.26 & 28 & 70.86 & 17.96 & 28 & 80.71 & 15.29 & 2.21 & $.031 *$ \\
\hline
\end{tabular}

Table 3. BDI-II scores per gender

\begin{tabular}{|c|c|c|c|c|c|c|}
\hline & \multicolumn{2}{|c|}{$\begin{array}{c}\text { Female } \\
(n=28)\end{array}$} & \multicolumn{2}{|c|}{$\begin{array}{c}\text { Male } \\
(n=35)\end{array}$} & \multirow[t]{2}{*}{$t$} & \multirow[t]{2}{*}{$p$} \\
\hline & $M$ & $S D$ & $M$ & $S D$ & & \\
\hline BDI-II Total Score & 8.36 & 6.63 & 7.43 & 5.86 & 0.54 & .589 \\
\hline \multicolumn{7}{|l|}{ SELFCS } \\
\hline Self-kindness & 12.41 & 4.27 & 14.40 & 12.41 & -2.05 & $.045^{*}$ \\
\hline Common humanity & 12.48 & 3.92 & 13.29 & 12.48 & -0.91 & .366 \\
\hline Mindfulness & 11.11 & 3.48 & 12.32 & 11.11 & -1.62 & .113 \\
\hline Self-judgement & 16.75 & 4.34 & 14.69 & 16.75 & 2.06 & $.044^{*}$ \\
\hline Isolation & 13.52 & 3.53 & 10.85 & 13.52 & 3.36 & $.001 * *$ \\
\hline Over-identification & 13.78 & 3.36 & 11.26 & 13.78 & 2.94 & $.005^{* *}$ \\
\hline Total & 69.04 & 19.12 & 80.84 & 13.99 & -2.67 & $.010 *$ \\
\hline
\end{tabular}

A significant difference was found for symptomatology of depression as measured by BDI-II total score $\left(t_{(31)}=-2.10, p=.018\right)$ between participants having or not having previous treatment: patients with previous treatments tend to present higher scores of BDI-II.

The Without/Mild Depression and Moderate/Severe Depression groups were found to be significantly different regarding both the mean global score of self- compassion $\left(t_{(45)}=2.35, p=.023\right)$, as well as for the three negative dimensions of self-compassion: selfjudgment $\left(\mathrm{t}_{(51)}=-3.04, p=.004\right)$, isolation $\left(t_{(49)}=-2.16\right.$, $p=.036)$ and over-identification $\left(t_{(49)}=-3.05, p=.004\right)$. Patients with less severe symptoms of depression presented a higher global score of self-compassion and lower levels of the negative dimensions (Table 4).

Table 4. SELFCS dimensions scores per level of depression (according to BDI-II)

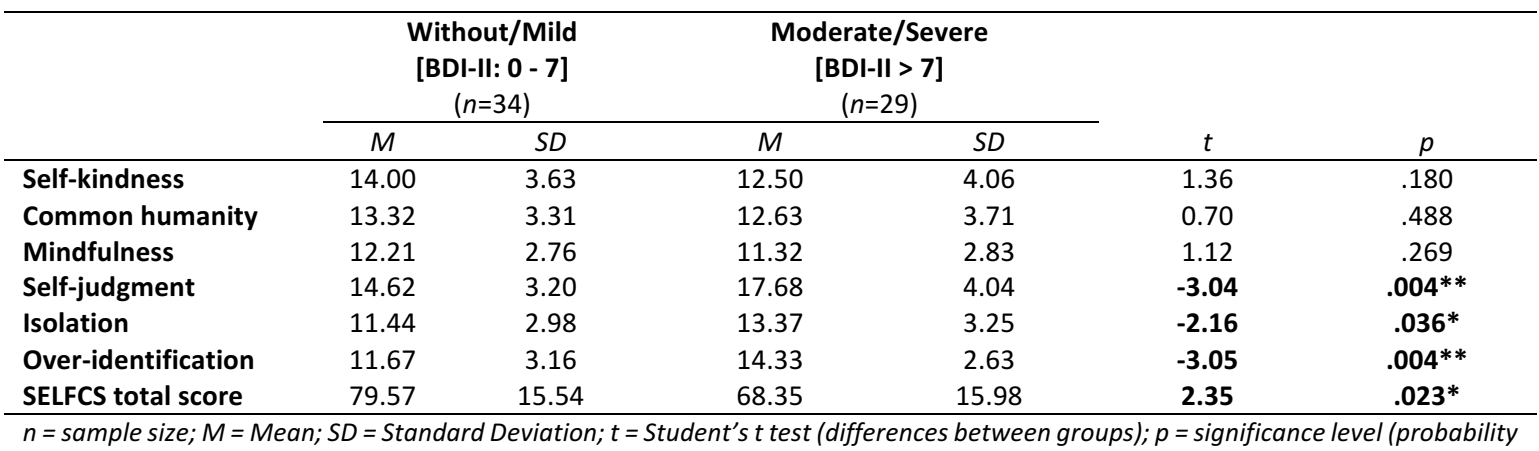

that the difference found is due to error; ${ }^{*} p<.05,{ }^{* *} p<.01$. Statistically significant differences in bold. 


\section{Associations between BDI-II and SELFCS in the total Sample}

Depression (BDI-II) overall score was found to hold a moderate negative correlation with global self-compassion (SELFC; $r=-.32, p=.029$ ). On the other side, depression was found to hold positive moderate correlations with both self-judgment $(r=.32, p=.020)$ and isolation ( $r=.31, p=.029 ;$ Table 5).

Table 5. Correlations between BDI-II scores and SELFCS dimensions scores

\begin{tabular}{lcccccccc}
\hline & 1 & 2 & 3 & 4 & 5 & 6 & 7 & 8 \\
\hline $\begin{array}{l}\text { BDI-II } \\
\quad \text { Depression }\end{array}$ & 1 & & & & & & & \\
SELFCS & & & & & & & & \\
$\quad$ Self-kindness & -.21 & 1 & & & & & & \\
$\quad$ Common humanity & -.17 & $.69^{* * *}$ & 1 & & & & & \\
$\quad$ Mindfulness & -.19 & $.63^{* * *}$ & $.70^{* * *}$ & 1 & & & \\
$\quad$ Self-judgement & $.33^{*}$ & $-.50^{* * *}$ & $-.34^{* *}$ & $-.30^{*}$ & 1 & & \\
$\quad$ Isolation & $.31^{*}$ & $-.54^{* * *}$ & $-.44^{* * *}$ & $-.48^{* * *}$ & $.63^{* * *}$ & 1 & & \\
$\quad$ Over-identification & .27 & $-.55^{* * *}$ & $-.50^{* * *}$ & $-.42^{* *}$ & $.80^{* * *}$ & $.67^{* * *}$ & 1 & \\
$\quad$ Total score & $-.32^{*}$ & $.84^{* * *}$ & $.77^{* * *}$ & $.76^{* * *}$ & $-.81^{* * *}$ & $-.81^{* * *}$ & $-.83^{* * *}$ & 1 \\
\hline$p=$ significance level $\left.{ }^{*} p<.05 ;{ }^{* *} p<.01 ;{ }^{* * *} p<.001\right)$. & & & & &
\end{tabular}

\section{Associations between BDI-II and SELFCS according to moment of treatment (In- and Post-treatment)}

In the In-treatment group, BDI-II overall score hold moderate negative correlations with the global score of self-compassion $(r=-.57, p=.007)$ and with the selfkindness dimension $(r=-.45, p=.020)$, and moderate positive correlations with the three negative dimensions of SELFCS: self-judgment $(r=.47, p=.013)$, isolation $(r=.53, p=.005)$ and over-identification ( $r=.47, p=.015)$. In the Post-Treatment group, no significant correlations were found between these variables.

Table 6. Correlations Between SELFCS Dimensions Scores and BDI-II Global Score According to Moment of Treatment (In and Post)

\begin{tabular}{lcc}
\hline & $\begin{array}{c}\text { In-Treatment } \\
(n=32)\end{array}$ & $\begin{array}{c}\text { Post-Treatment } \\
(n=31)\end{array}$ \\
\hline Self-kindness & $-.45^{*}$ & .02 \\
Common humanity & -.30 & .06 \\
Mindfulness & -.36 & .06 \\
Self-judgement & $.47^{*}$ & .11 \\
Isolation & $-.53^{* *}$ & .06 \\
Over-identification & $.47^{*}$ & -.03 \\
SELFCS total sample & $-.53^{* *}$ & -.01 \\
\hline$n=$ sample size; $p=$ significance level $\left({ }^{*} p<.05 ;{ }^{*} p<.01\right)$.
\end{tabular}

SEFLCS dimensions as predictors of BDI-II in the Inand Post-treatment groups

Three stepwise regression models were used: one for the total sample, one for the In-Treatment group and another for the Post-Treatment group. For each of these models, the different dimensions of self-compassion were used as predictors of depression symptoms. Taking into consideration the results obtained for the bivariate correlation, the common humanity and over-identification SELFCS dimensions were left out of the regression analyses.

For the total sample, self-judgment was found to be a significant predictor $(\beta=.32, p=.025)$, explaining $10 \%$ of the variance of BDI-II overall score (Adjusted $\left.R^{2}=.08, F_{(1.47)}=2.36, p=.025\right)$.

For the In-treatment group, the only significant predictor was isolation ( $\beta=.54, p=.006)$, explaining $29 \%$ of the variance of depression symptoms (Adjusted $R^{2}=0.26, F_{(1.23)}=9.36, p=.006$ ).

Lastly, there were no significant predictors of depression symptoms (as measured by BDI-II) in the Posttreatment group.

\section{Discussion}

The main goal of the present study was to characterize and compare self-compassion and symptomatology of depression in two distinct moments of intervention: during (In-treatment) and after treatment (one-year Post-treatment). 
When comparing the SELFCS index of self-compassion between the In-treatment and Post-Treatment groups, it was found that the Post-treatment group presented higher levels of self-kindness and, on the other hand, lower levels of over-identification.

It is of particularly interesting to observe the high scores for over-identification in the In-treatment group, indicating the inability to create distance from a negative situation (Neff, 2003a), which can lead to the amplification and prolongation of suffering, with a significant positive evolution observed for the Posttreatment group.

However, no significant differences were found between groups regarding symptomatology of depression, as assessed by the overall score of BDI-II, which may be explained by the reduced sample size or even by how the therapeutic intervention may have already improved the symptomatology of depression diagnosed at the beginning of treatment, in part with the promotion of self-compassion. To better understand the effectiveness of the therapeutic model in treating depression, further studies have to be conducted using a longitudinal design and measuring depressive symptoms before, and not only during treatment (i.e., already after some intervention sessions). The results regarding self-compassion, however, lend some credence to the effectiveness of the intervention model for the promotion of the studied self-compassion dimensions which, according to the literature, contribute for better general mental health (Neff \& Vonk, 2009).

In view of the results found in the Post-treatment group, it would seem probable that the therapeutic intervention allowed the development of competences necessary for the adoption of a more objective perspective, leading eventually to lower levels of overidentification. As already discussed in the literature, self-compassion can reduce suffering by serving as a healthy emotion regulation strategy (Neff, 2003b). With regard to gender, significant differences were found for the complete sample, with women showing lower levels of global self-compassion and self-kindness, in line with other studies that have found similar results (Neff, 2003b; Neff, Hseih, \& Dejitthirat, 2005;
Neff \& McGehee, 2010; Raes, 2010; Yarnell \& Neff, 2013). These results must be anyway interpreted with caution due to the fact that other studies have not found significant gender differences (Iskender, 2009; Neff et al., 2008; Neff \& Pommier, 2013). A recent meta-analysis conducted by Yarnell and colleagues (2015), revealed a significant difference between genders; but it also revealed that this difference was larger when samples had greater representation of ethnic minorities. This may indicate that the difference in self-compassion between genders could be mediated by other variables that have not yet been sufficiently studied. In the present study, women not only revealed lower levels of self-compassion but also higher levels of self-judgment, isolation and overidentification (Neff, 2003b).

The group of participants with previous treatments was found to have higher levels of symptomatology of depression. These results can be explained by the fact that a more severe depression could present greater resistance to treatment and requiring additional or recurrent treatments. Some studies indicate that, even when the gains are maintained for five years after the initial treatment, $58 \%$ of patients with depression recur in the following 10 years (Mueller et al., 1999).

It was also possible to verify significant differences according to the depression severity scores (again, complete sample in analysis), with without/mild depression associated with higher levels of selfcompassion, when compared with moderate/severe depression. The moderate/severe depression group showed higher levels of self-judgment, isolation and over-identification. These results are in line with the relevant literature regarding the relationship between self-compassion, its various dimensions and psychopathology (MacBeth \& Gumley, 2012; Raes, 2010). The study conducted by Krieger and colleagues (2016), which looked into the reciprocal effects between symptoms of depression and self-compassion, found that lack of self-compassion significantly predicted subsequent symptoms of depression, whereas the reverse was not true. It would be interesting for future studies to explore if levels of self-compassion could predict not only symptomatology of depression and the presence of major depressive disorder, but also 
the severity of the depression and maybe even the response to treatment.

When exploring the associations between the studied variables (for the total sample), depression was found to be negatively associated with global self-compassion and, on the other hand, positively associated with both self-judgment and isolation. These results are in line with the literature (Neff et al., 2007; MacBeth \& Gumley, 2012), despite the fact that different dimensions of self-compassion can be found to be associate with depression depending on the specific characteristics of the studies (e.g., population of study, sample size).

It is important to highlight that various studies have found self-compassion to be positively associated with lower levels of psychopathology (not only depression), while its negative dimensions (self-judgment, isolation and over-identification) have been found to be positively associated with psychopathology (Van Dam et al., 2011).

The same analysis, when conducted for each of the groups (In-treatment and Post-treatment), indicated similar, but more heterogeneous results. In the Intreatment group, there was a significant negative association between symptomatology of depression and the global score of self-compassion, as well as between symptomatology of depression and selfkindness. In this same group, it was found a significant positive association between depression symptoms and the three negative dimensions of self-compassion (self-judgment, isolation and over-identification). No significant associations were found between these variables in the Post-treatment group, which is an intriguing result. Other studies (e.g., Krieger et al., 2013) have found that the associations between self-compassion, its components and depression (or symptoms of depression), are significant for both clinical and non-clinical samples, depressed and non-depressed participants. The fact that this association was not present in the Post-treatment group is unexpected and, we think, justifies further studies that would allow a more in-depth exploration of the relationship between self-compassion and depression (and possibly other psychopathologies) after treatment.

Lastly, when exploring the dimensions of self-compassion as possible predictors of depressive symptomatology for the total sample, it was found that higher levels of self-judgment predict higher levels depression symptoms, explaining $10 \%$ of the variation. This result is also in line with studies that have looked into this same relationship (Gilbert, 2009; Gilbert \& Procter, 2006). However, there are studies in clinical samples that have found self-judgment to have a greater predictive power. In a study conducted by Van Dam, Sheppard, Forsyth and Earleywine (2011), with 504 depressed and/or anxious patients, self-judgment explained $36 \%$ of the severity of the depressive symptomatology. The difference could perhaps be explained by the sample size and by the fact that about half of our sample had already completed the treatment for depression.

When studying the separated groups, results showed that in the In-treatment group, isolation is a significant predictor of symptomatology of depression, explaining $29 \%$ of the variance in depression. This result is consistent with studies that explored the associations of this variable among general (Mills, Gilbert, Bellew, McEwan, \& Gale, 2007; Neff et al., 2008) and clinical populations (Krieger et al., 2013; Van Dam et al., 2011). A more recent study conducted with general population from Germany, by Korner and colleagues (2015), found that isolation explained $18 \%$ of the variance of depression symptoms severity; their lower predictive power (than ours) may be explained by the fact that their study wasn't done in a clinical population.

These results have practical importance and underline the role of isolation, even during treatment in a residential context, in predicting depression and also in predicting the effectiveness of the treatment. Isolation is one of the negative dimensions of selfcompassion and should not be considered as equivalent to the social isolation not to the feeling of 
loneliness (intricately linked with depression in different populations; e.g. Matthews et al., 2016). Isolation as a self-compassion dimension is defined as the egocentric fallacy that "it's just me" instead of framing experiences of suffering in light of the shared human experience (Neff, 2016). In this line, the promotion of a feeling of common humanity (vs. isolation) seems to be an important factor to the outcome of treatment in depression, and it would be interesting to study this phenomenon more in-depth.

In the In-treatment group, no other self-compassion dimensions were found to be significant predictors of depression symptoms, nor even self-judgment, which was found to be a predictor of depression for the total sample. This discrepancy could be due to the sample size of the In-treatment group. Also, in the Post-treatment group, none of the dimensions of selfcompassion were found to be significant predictors of depression.

The results of the present study should be interpreted taking into consideration its context, particularly when interpreting the results regarding the different moments of treatment: In-treatment and Post-treatment. It is pertinent to understand how the studied variables are integrated in the therapeutic model adopted by the therapeutic unit where the data was collected. The therapeutic model, designated Change \& Grow ${ }^{\oplus}$, is based on five principles (Truth, Acceptance, Gratitude, Love and Responsibility) and incorporates various therapeutic strategies promoters of self-compassion. The model, created and developed in VillaRamadas since 2005, has followed the conceptual evolution of different psychological approaches, translating into practice positive dimensions of self-compassion and contributing to the promotion of adaptive life skills.

There are limitations in the present study that should be highlighted: (a) data were collected from a single private therapeutic unit, which segments the target audience, conditioning the data-framing against the general population; (b) the possibility that participants that were included in the Post-treatment group could have been meanwhile subjected to other interventions (psychotherapeutic and/or pharmacological), outside the therapeutic unit; (c) the fact that the present study was conducted with a cross-sectional design, not allowing, therefore, the establishment of temporal causal relations; (d) the somewhat small sample size that may have impaired to observe significant differences between groups for some of the analysis that were performed (as stated above).

Main results of the present study are in line with the available literature concerning the relationship between self-compassion, its components and symptomatology of depression. Regarding the therapeutic model in question and its effectiveness for both depression and other psychopathologies, further studies must be conducted.

\section{Declaration of Conflicting Interests}

The authors declare no conflicts of interest with respect to the research, authorship, and/or publication of this article.

\section{References}

American Psychiatric Association (APA). 1994. Diagnostic and statistical manual of mental disorders (4th ed.). Washington, DC: Author.

American Psychiatric Association (APA). 2013. Diagnostic and statistical manual of mental disorders (5th ed.). Washington, DC: Author.

Barnard, L. K., \& Curry, J. F. (2011). Self-compassion: conceptualizations, correlates, and interventions. Review of General Psychology, 15, 289-303. https://doi.org/10.1037/a0025754.

Bebbington, P. E. (1996). The origins of sex differences in depressive disorder: bridging the gap. International Review of Psychiatry, 8, 295 - 332. https://doi.org/10.3109/09540269 609051547.

Bebbington, P. E. (1998). Sex and depression. Psychological Medicine, 28, 1 - 8. https://doi.org/10.1017/s003329179700 6065.

Beck, A. T., Ward, C. H., Mendelson, M., Mock, J., \& Erbaugh, J. (1961). An inventory for measuring depression. Archives of General Psychiatry, 4(6), 561-571. http://doi.org/10.1001/ archpsyc.1961.01710120031004

Beck, A. T., Steer, R. A., \& Brown, G. K. (1996). Manual for the Beck Depression Inventory-II. San Antonio, TX: Psychological Corporation. https://doi.org/10.1037/t00742-000.

Bifulco, A., Brown, G. W., Moran, P., \& Ball, C. (1998). Predicting depression in women: the role of past and present vulnerability. Psychological Medicine, 28, 39-50. https://doi.org/ $10.1017 / \mathrm{s} 0033291797005953$. 
Castilho, P., \& Gouveia, J. P. (2011). Auto-Compaixão: Estudo da validação da versão portuguesa da Escala da Auto-Compaixão e da sua relação com as experiências adversas na infância, a comparação social e a psicopatologia. Psychologica. 1(54), 203-230. https://doi.org/10.14195/16478606_54_8.

Coutinho, M. P. L., Gontiès, B., Araújo, L. F., \& Sá, R. C. N. (2003). Depressão, um sofrimento sem fronteira: representações sociais entre crianças e idosos. Psico-USF, 8(2), 183-192. https://doi.org/10.1590/S1413-82712003000200010.

Galante, J., Galante, I., Bekkers, M. J., \& Gallacher, J. (2014). Effect of kindness-based meditation on health and well-being: a systematic review and meta-analysis. Journal of Consulting and Clinical Psychology, 82, 1101-1114. https://doi.org/ 10.1037/a0037249.

Gilbert, P. (2009). Introducing compassion-focused therapy. Advances in psychiatric treatment, 15(3), 199-208. https://doi.org/10.1192/apt.bp.107.005264.

Gilbert, P., \& Procter, S. (2006). Compassionate mind training for people with high shame and self-criticism: overview and pilot study of a group therapy approach. Clinical Psychology \& Psychotherapy, 13(6), 353-379. https://doi.org/10.1002/ cpp.507.

Gusmão, R.M., Xavier, M., Heitor, M.J., Bento, A., \& Almeida, J.M. (2005). O peso das perturbações depressivas: aspectos epidemiológicos globais e necessidades de informação em Portugal. Acta Médica Portuguesa, 18(2), 129-46.

Hofmann, S. G., Grossman, P., \& Hinton, D. E. (2011). Lovingkindness and compassion meditation: Potential for psychological interventions. Clinical Psychology Review, 31, 11261132. https://doi.org/10.1016/j.cpr.2011.07.003.

Horn, G. L. (2012). An investigation into the effects of cognitive behavioural therapy on patients with chronic depression: a small case series. Psychology Research and Behavior Management, 5, 123-129. https://doi.org/10.2147/prbm.s31774.

Iskender, M. (2009). The relationship between self-compassion, self-efficacy, and control belief about learning in Turkish university students. Social Behavior and Personality, 37, 711720. https://doi.org/10.2224/sbp.2009.37.5.711.

Kaplan, H. I., \& Sadock, B. J. (1997). Tratado de psiquiatria. Porto Alegre: Artmed.

Kelly, M., Tyrka, A., Price, L., \& Carpenter, L. (2008). Sex differences in the use of coping strategies: predictors of anxiety and depressive symptoms. Depression and Anxiety, 25(10), 839-846. https://doi.org/10.1002/da.20341.

Kessler, R. C., Berglund, P., Demler, O., Jin, R., Merikangas, K. R., \& Walters, E. E. (2005). Lifetime prevalence and age-ofonset distributions of DSM-IV disorders in the National Comorbidity Survey Replication. Archives of General Psychiatry, 62, 593-602. https://doi.org/10.1001/archpsyc.62.6.593.

Keyes, C. L. M. (2005). Mental illness and/or mental health? Investigating axioms of the complete state model of health. Journal of Consulting and Clinical Psychology, 73(3), 539-548. https://doi.org/10.1037/0022-006x.73.3.539.

Kline, R. (2005). Principles and practice of structural equations modeling (2nd ed.). London: Guilford Press.

Korner, A., Coroiu, A., Copeland, L., Gomez-Garibello, C., Albani, C., \& Zenger, M. (2015). The role of self-compassion in buffering symptoms of depression in the general population. PLOS One, 10(10). https://doi.org/10.1371/journal.pone.0136598.

Krieger, T., Altenstein, D., Baettig, I., Doerig, N., \& Holtforth, M.G. (2013). Self-compassion in depression: Associations with depressive symptoms, rumination, and avoidance in depressed outpatients. Behavior Therapy, 44, 501-513. https://doi.org/10.1016/j.beth.2013.04.004.

Krieger, T., Berger, T., \& Holtforth, M.G. (2016). The relationship of self-compassion and depression: Cross-lagged panel analyses in depressed patients after outpatient therapy. Journal of Affective Disorders, 202, 39-45. https://doi.org/10.1016/j.jad.2016.05.032.

Lamers, S. M. A., Westerhof, G. J., Bohlmeijer, E. T., ten Klooster, P. M., \& Keyes, C. L. M. (2011). Evaluating the psychometric properties of the Mental Health Continuum-Short Form (MHC-SF). Journal of Clinical Psychology, 67(1), 99-110. https://doi.org/10.1002/jclp.20741.

Leaviss, J., \& Uttley, L. (2014). Psychotherapeutic benefits of compassion-focused therapy: an early systematic review. Psychological Medicine, 45(5), 927-945. https://doi.org/ $10.1017 / \mathrm{s} 0033291714002141$.

Lutz, A., Greischar, L., Rawlings, N., Ricard, M., \& Davidson, R. (2004). Long-term meditators self-induce high-amplitude gamma synchrony during mental practice. Proceedings of the National Academy of Sciences of the United States of America, 101(46). https://www.pnas.org/content/101/46/16369.

MacBeth, A., \& Gumley, A. (2012). Exploring compassion: A meta-analysis of the association between self-compassion and psychopathology. Clinical Psychology Review, 32(6), 545552. https://doi.org/10.1016/j.cpr.2012.06.003.

Matthews, T., Danese, A., Wertz, J., Odgers, C. L., Ambler, A., Moffitt, T. E., \& Arseneault, L. (2016). Social isolation, loneliness and depression in young adulthood: a behavioural genetic analysis. Social Psychiatry and Psychiatric Epidemiology, 51, 339-348. https://doi.org/10.1007/s00127-0161178-7.

Michalak, E. E., \& Lam, R. W. (2002). Breaking the myths: new treatment approaches for chronic depression. Canadian Journal of Psychiatry, 47(7), 635-643. https://doi.org/10.1177/ 070674370204700705

Mills, A., Gilbert, P., Bellew, R., McEwan, K., \& Gale, C. (2007). Paranoid beliefs and self-criticism in students. Clinical Psychology \& Psychotherapy, 14(5), 358-364. https://doi.org/10.1002/cpp.537.

Mueller, T. I., Leon, A. C., Keller, M. B., Solomon, D. A., Endicott, J., Coryell, W., ... Maser, J. D. (1999). Recurrence after recovery from major depressive disorder during 15 years of observational follow-up. The American Journal of Psychiatry, 156(7), 1000-1006. doi: 10.1176/ajp.156.7.1000

Neff, K. (2003a). Self-Compassion: An Alternative Conceptualization of a Healthy Attitude Toward Oneself. Self and Identity, 2(2), 85-101. https://doi.org/10.1080/1529886030 9032.

Neff, K. (2003b). The development and validation of a scale to measure self-compassion. Self and Identity, 2(3), 223-250. https://doi.org/10.1080/15298860309027.

Neff, K. D. (2012). The science of self-compassion. In C. Germer \& R. Siegel (Eds.), Compassion and Wisdom in Psychotherapy (pp. 79-92). New York: Guilford Press.

Neff, K. D. (2015). The self-compassion scale is a valid and theoretically coherent measure of self-compassion. Mindfulness, 7(1), 264-274. https://doi.org/10.1007/s12671-015-0479-3.

Neff, K. D. (2016). Does self-compassion entail reduced selfjudgment, isolation, and over-identification? A response to Muris, Otgaar, and Petrocchi. Mindfulness, 7(3), 791-797. https://doi.org/10.1007/s12671-016-0531-y. 
Neff, K. D., Hsieh, Y. -P., \& Dejitterat, K. (2005). Self-compassion, achievement goals, and coping with academic failure. Self and Identity, 4, 263-287. https://doi.org/10.1080/13576 500444000317.

Neff, K. D., Kirkpatrick, K.L., \& Rude, S. S. (2007). Self-compassion and adaptive psychological functioning. Journal of Research in Personality, 41, 139-154. https://doi.org/ 10.1016/j.jrp.2006.03.004

Neff, K. D., \& McGehee, P. (2010). Self-compassion and psychological resilience among adolescents and young adults. Self and Identity, 9, 225-240. https://doi.org/10.1080/15298860 902979307.

Neff, K. D., Pisitsungkagarn, K., \& Hsieh, Y. (2008). Self-compassion and self-construal in the United States, Thailand, and Taiwan. Journal of Cross-Cultural Psychology, 39, 267-285. https://doi.org/10.1177/0022022108314544.

Neff, K. D., \& Pommier, E. (2013). The relationship between self-compassion and other-focused concern among college undergraduates, community adults, and practicing meditators. Self and Identity, 12, 160-176. https://doi.org/10.1080/ 15298868.2011.649546.

Neff, K. D., Rude, S. S., \& Kirkpatrick, K. L. (2007). An examination of self-compassion in relation to positive psychological functioning and personality traits. Journal of Research in Personality, 41(4), 908-916. https://doi.org/10.1016/j.jrp.2006. 08.002 .

Neff, K. D., \& Vonk, R. (2009). Self-Compassion Versus Global Self-Esteem: Two Different Ways of Relating to Oneself. Journal of Personality, 77(1), 23-50. https://doi.org/10.1111/ j.1467-6494.2008.00537.x.

Parker, G., Wilhelm, K., \& Asghari, A. (1997). Early onset depression: the relevance of anxiety. Social Psychiatry and Psychiatric Epidemiology, 32, 30-37. https://doi.org/10.1007/ bf00800665.

Pestana, M. H., \& Gageiro, J. N. (2008). Análise de dados para ciências sociais: a complementaridade do SPSS (5th ed.). Lisboa: Edições Sílabo.

Piccinelli, M., \& Wilkinson, G. (2000). Gender differences in depression. The British Journal of Psychiatry, 177(6), 486-492. https://doi.org/10.1192/bjp.177.6.486.

Ponciano, E., Cardoso, I., \& Pereira, A. (2004). Adaptação de uma versão experimental em língua portuguesa do Beck Depression Inventory Second Edition (BDI-II) em estudantes do Ensino superior. In: Acção social e aconselhamento psicológico no ensino superior e intervenção (p. 329-337). Coimbra: SASUC.

Raes, F. (2010). Rumination and worry as mediators of the relationship between self-compassion and depression and anxiety. Personality and Individual Differences, 48(6), 757761. https://doi.org/10.1016/j.paid.2010.01.023.

Raes, F. (2011). The effect of self-compassion on the development of depression symptoms in a non-clinical sample.
Mindfulness, 2, 33-36. https://doi.org/10.1007/s12671-0110040-y.

Raque-Bogdan, T., Ericson, S. K., Jackson, J., Martin, H. M., \& Bryan, N. A. (2011). Attachment and mental and physical health: Self-compassion and mattering as mediators. Journal of Counseling Psychology, 58, 272-278. https://doi.org/ 10.1037/a0023041.

Rodgers, B. (1994). Pathways between parental divorce and adult depression. Journal of Child Psychology and Psychiatry, 35, 1289 -1308. https://doi.org/10.1111/j.1469-7610.1994. tb01235.x.

Trompetter, H., Kleine, E., \& Bohlmeijer, E. T. (2016). Why does positive mental health buffer against psychopathology? An exploratory study on self-compassion as a resilience mechanism and adaptive emotion regulation strategy. Cognitive Therapy and Research, 41, 459-468. https://doi.org/10.1007/ s10608-016-9774-0.

Van Dam, N. T., Sheppard, S. C., Forsyth, J. P., \& Earleywine, M. (2011). Self-compassion is a better predictor than mindfulness of symptom severity and quality of life in mixed anxiety and depression. Journal of Anxiety Disorders, 25(1), 123-30. https://doi.org/10.1016/j.janxdis.2010.08.011.

Veijola, J., Puukka, P., Letinen, V., Moring, J., Lindholm, T., \& Vaisanen, E. (1998). Sex differences in the association between childhood experiences and adult depression. Psychological Medicine, 28, 21 -27. https://doi.org/10.1017/ s0033291797006089.

Weich, S., Brugha, T., King, M., McManus, S., Bebbington, P., Jenkins, R., ... Stewart-Brown, S. (2011). Mental well-being and mental illness: Findings from the adult psychiatric morbidity survey for England 2007. British Journal of Psychiatry, 199(1), 23-28. https://doi.org/10.1192/bjp.bp.111.091496.

Wispe, L. (1991). The psychology of sympathy. New York: Plenum.

World Health Organization (WHO). 2017. Depression and Other Common Mental Disorders: Global Health Estimates. Geneva: Author.

Xavier, M., Baptista, H., Mendes, J. M., Magalhães, P., \& Caldasde-Almeida, J. M. (2013). Implementing the World Mental Health Survey Initiative in Portugal: rationale, design and fieldwork procedures. International Journal of Mental Health Systems, 7, 19. https://doi.org/10.1186/1752-4458-7-19.

Yarnell, L. M., \& Neff, K. D. (2013). Self-compassion, interpersonal conflict resolutions, and well-being. Self and Identity, 12, 146-159. https://doi.org/10.1080/15298868.2011.6495 45.

Yarnell, L. M., Stafford, R., Neff, K. D., Reilly, E., Knox, M. C., \& Mullarkey, M. (2015). Meta-Analysis of Gender Differences in Self-Compassion. Self and Identity, 14(5), 499-520. https://doi.org/10.1080/15298868.2015.1029966. 